\title{
Confirmed case of Zika virus congenital infection, Spain, March 2016
}

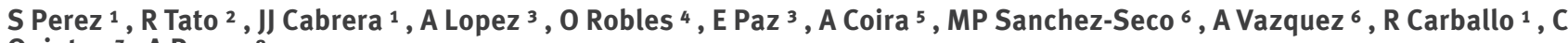

Quintas $^{7}$, A Pousa 8

1. Microbiology Department, University Hospital of Vigo, Spain

2. Microbiology Department, University Hospital of Pontevedra, Spain

3. Gynecology Department, Lucus Augusti Hospital, Lugo, Spain

4. Pathology Department, Lucus Augusti Hospital, Lugo, Spain

5. Microbiology Department, Lucus Augusti Hospital, Lugo, Spain

6. Arbovirus and Imported Viral Diseases, Virology Area, National Center of Microbiology (CNM), Carlos III Health Institute (ISCIII), Majadahonda, Madrid, Spain

7. Preventive Medicine Department, Lucus Augusti Hospital, Lugo, Spain

8. General Subdirection for Epidemiology and Information Systems, General Direction of Public Health, Consellería de Sanidade, Santiago de Compostela, Spain

Correspondence: Sonia Perez (sonia.perez.castro@sergas.es)

We describe Zika virus (ZIKV) vertical transmission in an imported case in Spain, in a 17-week pregnant woman. ZIKV IgG, IgM and RNA were detected in serum in week 17. At 19 weeks, ultrasound scan revealed fetal malformations and ZIKV was detected in the amniotic fluid. Pregnancy was terminated at week 21; autopsy of the fetus revealed bilateral hydrocephalus, brain microcalcifications and arthrogryposis multiplex congenita. ZIKV was detected in the umbilical cord and brain tissue.

\section{Case description}

A pregnant woman in her mid-twenties (week 17 of pregnancy), from Venezuela, was admitted to the Gynaecology Department of a hospital in Spain, for routine follow up, in March 2016, while she was visiting Spain. Her medical history was uneventful apart from a generalised skin rash in January 2016, at eight weeks of gestational age. This led us to investigate a ZIKV infection, given the epidemiological situation in Venezuela. The rash had lasted for 48 hours but there was no microbiological diagnosis. At 12 weeks of gestational age, the ultrasound scan was normal, and the results of laboratory tests for HIV, Treponema pallidum and Toxoplasma gondii were negative.

Serum samples were collected upon hospital admission in March and recent ZIKV infection was diagnosed by serology and molecular biology. ZIKV IgG and IgM antibodies were detected by indirect immune fluorescence test (Euroimmun Arboviral Fever Mosaic 2, Luebeck, Germany). ZIKV IgG antibodies were confirmed by plaque reduction neutralization test (PRNT). NS2A protein gen of ZIKV was detected $(2.4 \times 104$ copies $/ \mathrm{mL})$ by real-time quantitative RT-PCR using Light Mix Modular ZikaVirus (Tib Molbiol, Berlin, Germany) and Light Cycler Multiplex RNA Virus Master (Roche Diagnostics, Mannheim, Germany) in a Cobas Z 480 analyser (Roche Diagnostics, Indianapolis, United States). Extraction of nucleic acids was performed with the MagNA Pure Compact Nucleic Acid Isolation Kit I (Roche Diagnostics, Indianapolis, United States). Ultrasound scan at 19 weeks of gestational age showed fetal hydrocephalus with dilation of both lateral ventricles (Figure 1), and stiffness and severe contractures of the four extremities compatible with arthrogryposis multiplex congenita (AMC) (Figure 2).

Amniotic fluid was obtained by amniocentesis. Chromosomal abnormalities were discarded by array comparative genomic hybridisation and karyotype analysis. ZIKV RNA was detected in amniotic fluid (9.1 x104 copies $/ \mathrm{mL}$ ) by real-time quantitative RT-PCR. Toxoplasma gondii, rubella virus, cytomegalovirus, herpes virus, erythrovirus B19 and measles virus infections were discarded by PCR in amniotic fluid.

Due to severe malformations and brain disease, the neonatal health prognosis was poor. The patient asked for voluntary termination of the pregnancy, and the procedure was approved by national and hospital ethics committees. Medical termination of the pregnancy was performed at 21 weeks of gestation. Autopsy of the female fetus ( $295 \mathrm{~g}$ ) showed no microcephaly (cranial, thoracic and abdominal circumference were $17 \mathrm{~cm}$, $16 \mathrm{~cm}$ and $14 \mathrm{~cm}$ respectively, normal for sex and gestational age) but confirmed AMC with flexion contracture and deformity of joints of all four limbs, extreme 


\section{FIGURE 1}

Ultrasound scan on fetal skull showing bilateral hydrocephalus, case of vertical transmission of Zika virus infection, gestation week 19, imported to Spain, March 2016

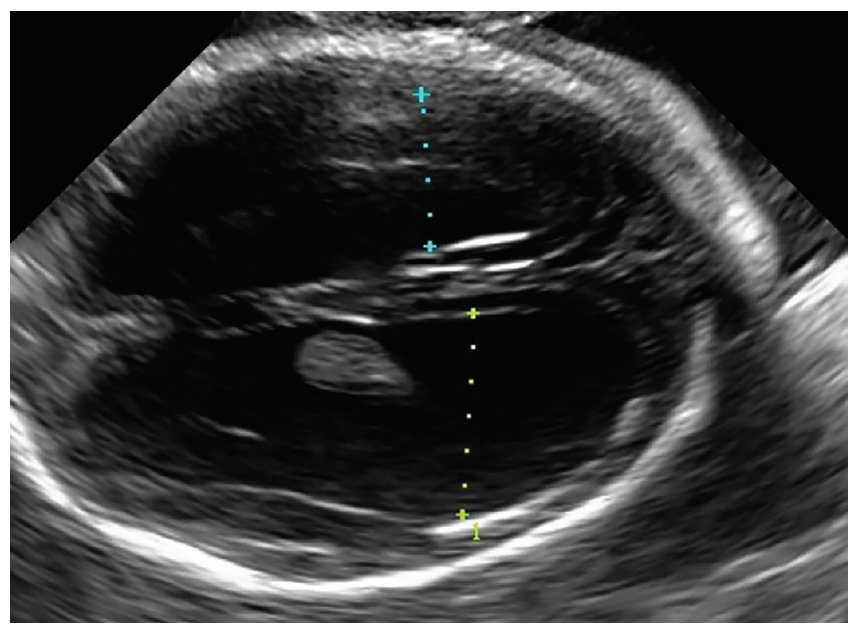

Ventricular measurements $14.3 \mathrm{~mm}$ (yellow) and $10.7 \mathrm{~mm}$ (blue) (norm: $\leq 10 \mathrm{~mm}$ )

\section{FIGURE 2}

Ultrasound scan on fetal extremities, case of vertical transmission of Zika virus infection, gestation week 19, imported to Spain, March 2016

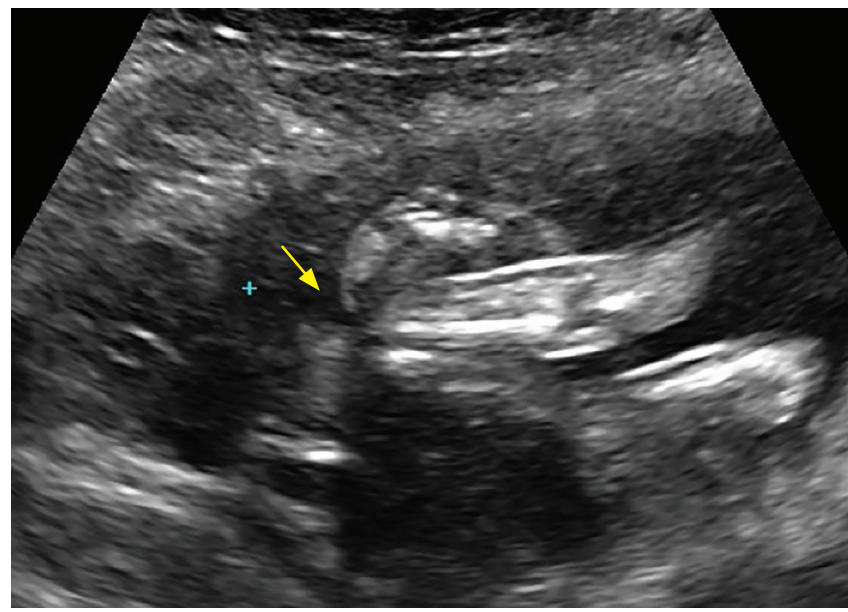

The arrow indicates severe contracture and deformation with extreme bending and twisting of the wrist.

flexion of hips and crossed femurs. Under-developed muscles with replacement of muscle by adipose tissue and fibrous proliferation in interarticularis spaces were also found. In addition, fetal hydrocephalus with dilation of both lateral ventricles, cerebral cortex $2.5 \mathrm{~mm}$ thick and multiple calcifications at cortical level and brainstem were diagnosed (Figure 3).

ZIKV real-time quantitative RT-PCR was performed in placenta, umbilical cord and brain tissue samples, as previously described. Before nucleic acid extraction, ca $10 \mathrm{mg}$ of tissue were treated with $50 \mu \mathrm{L}$ of proteinase $\mathrm{K}$ at $56^{\circ} \mathrm{C}$ until sample digestion, and then heated at $95^{\circ} \mathrm{C}$ for $10 \mathrm{~min}$ to inactivate proteinase $\mathrm{K}$. ZIKV RNA was detected in umbilical cord (threshold cycle, Ct: 36.7) and brain tissue (Ct: 22.1 ), but it was not detected in the placenta sample. For phylogenetic analysis, amplification of NS5 gene (192 bp) was performed from amniotic fluid sample as previously described [1] with Mega 7 Software and it was deposited in GenBank (accession number: KX358623). The sequence clustered within the Asian lineage.

\section{Background}

ZIKV is an arbovirus (arthropod-borne virus) of the genus Flavivirus. It was isolated for the first time in 1947 from the blood of a Rhesus monkey in the Zika forest (Uganda), but the infection was relatively unknown until the recent outbreak in South America. Prior to 2015, minor ZIKV outbreaks were reported in areas of Africa, south-east Asia and the Pacific Islands [2]. In May 2015, the Pan American Health Organization (PAHO) issued an alert regarding the first confirmed ZIKV infections in Brazil [3], which quickly spread all over the South America continent.

\section{Discussion}

Local mosquito transmission of ZIKV infection was reported in Venezuela in November 2015 [4]. In January 2016, a total of 252 cases of Guillain-Barré syndrome with a spatiotemporal association to Zika virus were reported. Zika virus infection was confirmed in three of them [5].

Phylogenetic analysis based on the conserved region $\mathrm{NS}_{5}$ has revealed the existence of two major lineages: the African lineage that includes the African strains and the Asian lineage which has recently emerged in the Pacific and the Americas including the Asian and American strains [6]. In this case, phylogenetic analysis showed that ZIKV strain isolated from this patient belonged to the Asian lineage.

The illness caused by ZIKV, commonly named Zika virus disease (ZVD), usually has a benign cause and presents with signs and symptoms similar to other arbovirus infections such as dengue virus (DENV) and chikungunya virus (CHKV): mild fever, exanthema, arthralgia and/or non-purulent conjunctivitis. Recently, ZIKV infection has been associated with neurological complications, such as Guillain-Barré syndrome, but encephalitis or meningitis have also been reported [7]. The patient reported generalised skin rash compatible with ZIKV infection during her stay in Venezuela.

ZIKV is transmitted through mosquito bites of the genus Aedes, mainly Aedes aegypti, which is the most important vector in Asia and the Americas and in some regions in the Pacific. Other possible modes for human infection include sexual transmission and blood transfusion, and vertical transmission from mother to fetus can have serious consequences. If a pregnant woman 


\section{FIGURE 3}

Microphotography of the entire cerebral cortex thickness with abundant microcalcifications, case of vertical transmission of Zika virus infection, gestation week 21, imported to Spain, April 2016

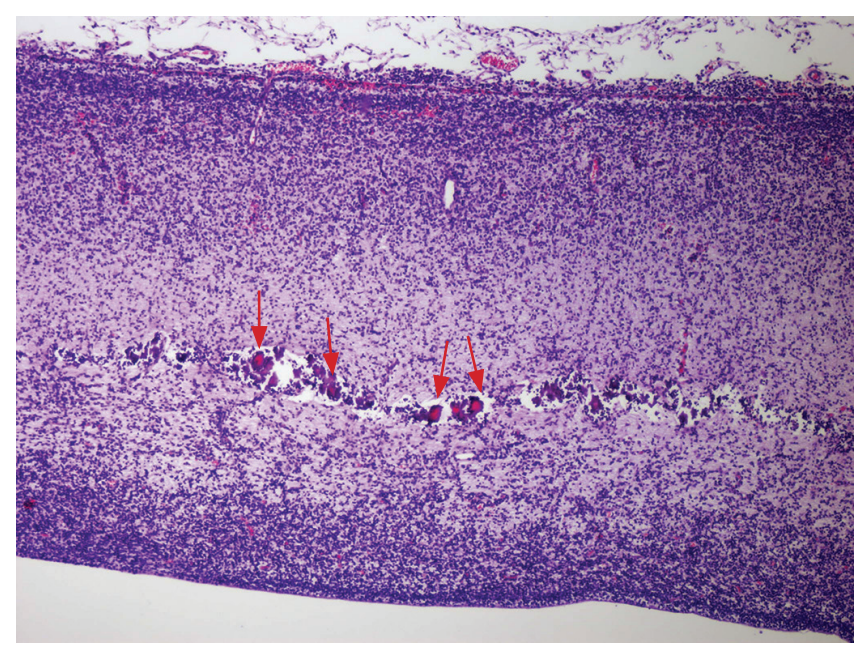

Arrows indicate microcalcifications.

acquires a ZIKV infection, the virus might cross placental barrier causing congenital infection. In this case, ZIKV RNA was detected in amniotic fluid, confirming that ZIKV crossed the placental barrier. When this happens, the fetus might develop brain damage including microcephaly and, less frequently, calcifications, ventriculomegaly or hydrocephalus, and other congenital malformations such as arthrogryposis [8].

Viraemia of ZIKV infection is relatively short, and viral RNA is usually detected in serum samples only around seven days after onset of symptoms. It is remarkable that in this case, ZIKV RNA was detected in the serum of the pregnant woman up to two months after the acute phase of the disease. Persistent viraemia was previously described in another case of congenital Zika transmission and it might be a consequence of high viral replication in the fetus [9].

The recent outbreaks in Brazil and French Polynesia indicate that the greatest risk of brain damage for the fetus is in the first trimester, often between seven and 13 weeks of gestation $[10,11]$. A preliminary report from Brazil indicated that fetal abnormalities were present in almost $30 \%$ of women with ZIKV infection during pregnancy [12]. In the case presented here, microcephaly was not present in the ultrasound scan at 19 weeks of gestation, probably due to the short gestational age, and this is in agreement with other reported cases in which microcephaly was not diagnosed until 27 to 35 weeks [12]. However, other malformations, such as hydrocephalus and arthrogryposis, were detected in this case. Presence of ZIKV RNA was detected in the umbilical cord and brain tissue but not in placenta as recently reported in another congenital case [13]. Another study showed that ZIKV is unlikely to access the fetal compartment by its direct replication in placental tissue. This might be explained due to the potent antiviral properties of type III interferons (IFNs), specifically IFN $\lambda_{1}$, which protects the human placental trophoblasts from viral infections, suggesting that ZIKV may invade the intrauterine cavity by unknown mechanisms that are independent of direct placental infection [14]. In this case, comparison of the $\mathrm{Ct}$ values between umbilical cord and brain tissue indicates a higher viral load (ca 10,000 times higher) in the central nervous system (CNS), showing a strong neurotropism of the virus, although the mechanism is not clear. A possible persistence of ZIKV in the fetal brain because of the immunologically secure milieu for the virus was suggested [15]. Additionally, recent studies found that neural progenitor cells are more susceptible to ZIKV infection than mature cortical neurons, explaining microcephaly and other abnormalities in the developing brain [16-18].

In the Zika situation report of the World Health Organization (WHO) on 6 June 2016 [19], only eleven countries or territories have reported microcephaly and/or CNS malformation cases potentially associated with ZIKV infection. The total number of cases reached 1,520 , and most of them are related to the recent outbreak in Brazil. In Spain, the Ministry of Health reported 141 cases of confirmed ZIKV infection on 6 June 2016, all of them imported from areas with active transmission [20]. Nineteen cases were pregnant women, but no evidence of intrauterine transmission was detected, except in this case. The first case of imported ZIKV infection and two cases of ZIKV infection in pregnant women in Spain, have been published recently [21,22]. Aside from this case, there has been only one other confirmed ZIKV congenital infection in Europe [15].

This case highlights the new challenge gynaecologists face when performing ultrasound in pregnant women originating from or having stayed in countries with risk of transmission of Zika. Nowadays, there is a considerable number of pregnant women who travel from South America; moreover, other pregnant women or their sexual partners may travel to affected areas. This may have an impact on prenatal care in Europe. Positive and negative predictive values of screening for Zika virus in amniotic fluid or maternal serum have not yet been established. Accurate and quick detection of the presence of Zika virus in maternal samples in collaboration with expert gynaecologists follow-up might help the early diagnosis of congenital Zika infections. It is important to carefully communicate risks associated with ZVD to those possibly concerned, and to improve the evidence base to perform well-informed risk assessments.

\section{Acknowledgements}

Authors are very grateful to the patient for providing informed consent for publication. Authors also thank Alonso P 
from the Microbiology Department of Lucus Augusti Hospital of Lugo, Spain, Ory F and all the staff from the 'Arbovirus and Imported Viral Diseases' laboratory of the National Center of Microbiology - Carlos III Health Institute, Majadahonda, Madrid, Spain. Authors specially thank the staff from the Microbiology Department of University Hospital of Vigo, Spain.

\section{Conflict of interest}

None declared.

\section{Authors' contributions}

Wrote the manuscript: SP, RT, AL, OR; performed laboratory investigations: $S P, R T, J J C, O R, A C, M P S S, A V, R C$; revised the manuscript: JJC, EP, AC, MPSS, AP, AV, RC, CQ; managed the patient: AL, OR, EP, AP, CQ.

\section{References}

1. Balm MND, Lee CK, Lee HK, Chiu L, Koay ESC, Tang JW. A diagnostic polymerase chain reaction assay for Zika virus.J Med Virol. 2012;84(9):1501-5. DOI: 10.1002/jmv.23241 PMID: 22825831

2. Waggoner JJ, Pinsky BA. Zika Virus: Diagnostics for an Emerging Pandemic Threat.J Clin Microbiol. 2016;54(4):860-7. DOI: 10.1128/JCM.00279-16 PMID: 26888897

3. Pan American Health Organization (PAHO) / World Health Organization (WHO). Epidemiological Alert. Zika virus infection. 7 May 2016. Washington, D.C.: PAHO/WHO. Available from: http://www.paho.org/hq/index.php?option=com docman\&task=doc_view\&Itemid $=270 \&$ gid=30075\&lang $=$ en

4. Pan American Health Organization (PAHO) / World Health Organization (WHO). Timeline of Emergence of Zika virus in the Americas. Washington, D.C.: PAHO/WHO; [Accessed Jun 2016]. Available from: http://www.paho.org/hq/index. php?option $=$ com_content \&view $=$ article $\& i d=11959 \&$ Itemid $=41$ 711\&lang=en

5. World Health Organization (WHO). Guillain-Barré syndrome - Colombia and Venezuela [Accessed 15 Jun 2016] Geneva: WHO. Available from: http://www.who.int/csr/ don/12-february-2016-gbs-colombia-venezuela/en/

6. Saiz J-C, Vázquez-Calvo Á, Blázquez AB, Merino-Ramos T, Escribano-Romero E, Martín-Acebes MA. Zika Virus: the Latest Newcomer.Front Microbiol. 2016;7:496. DOI: 10.3389/ fmicb.2016.00496 PMID: 27148186

7. Martínez de Salazar P, Suy A, Sánchez-Montalvá A, Rodó C, Salvador F, Molina I. Zika fever.Enferm Infecc Microbiol Clin. 2016;34(4):247-52. DOI: 10.1016/j.eimc.2016.02.016 PMID: 26993436

8. Schuler-Faccini L, Ribeiro EM, Feitosa IML, Horovitz DDG, Cavalcanti DP, Pessoa A, et al. , Brazilian Medical Genetics Society-Zika Embryopathy Task Force. Possible Association Between Zika Virus Infection and Microcephaly - Brazil, 2015. MMWR Morb Mortal Wkly Rep. 2016;65(3):59-62. DOI: 10.15585/mmwr.mm6503e2 PMID: 26820244

9. Driggers RW, Ho C-Y, Korhonen EM, Kuivanen S, Jääskeläinen AJ, Smura T, et al. Zika Virus Infection with Prolonged Maternal Viremia and Fetal Brain Abnormalities. N Engl J Med. 2016;374(22):2142-51. DOI: 10.1056/NEJMoa1601824 PMID: 27028667

10. Petersen LR, Jamieson DJ, Powers AM, Honein MA. Zika Virus.N Engl J Med. 2016;374(16):1552-63. DOI: 10.1056/NEJMra1602113 PMID: 27028561

11. Johansson MA, Mier-Y-Teran-Romero L, Reefhuis J, Gilboa SM, Hills SL. Zika and the Risk of Microcephaly.N Engl J Med. 2016;NEJMp1605367. DOI: 10.1056/NEJMp1605367 PMID: 27222919

12. Brasil P, Pereira JP Jr, Raja Gabaglia C, Damasceno L, Wakimoto M, Ribeiro Nogueira RM, et al. Zika Virus Infection in Pregnant Women in Rio de Janeiro - Preliminary Report. N Engl J Med. 2016; NEJMoa1602412. http://dx.doi.org/DOI: 10.1056/ NEJMoa1602412 PMID:26943629

13. Sarno M, Sacramento GA, Khouri R, do Rosário MS, Costa F, Archanjo G, et al. Zika Virus Infection and Stillbirths: A Case of Hydrops Fetalis, Hydranencephaly and Fetal Demise. PLoS
Negl Trop Dis. 2016;10(2):eooo4517. DOI: 10.1371/journal. pntd.0004517 PMID: 26914330

14. Bayer A, Lennemann NJ, Ouyang Y, Bramley JC, Morosky S, Marques ETDA, et al. Type III Interferons Produced by Human Placental Trophoblasts Confer Protection against Zika Virus Infection. Cell Host Microbe. 2016;19(5):705-12. DOI: 10.1016/j. chom.2016.03.008 PMID: 27066743

15. Mlakar J, Korva M, Tul N, Popović $M$, Poljšak-Prijatelj M, Mraz J, et al. Zika Virus Associated with Microcephaly. N Engl J Med. 2016;374(10):951-8. DOI: 10.1056/NEJMoa1600651 PMID: 26862926

16. Miner JJ, Diamond MS. Understanding How Zika Virus Enters and Infects Neural Target Cells.Cell Stem Cell. 2016;18(5):559 60. DOI: $10.1016 /$ j.stem.2016.04.009 PMID: 27152436

17. Nowakowski TJ, Pollen AA, Di Lullo E, Sandoval-Espinosa C, Bershteyn M, Kriegstein AR. Expression Analysis Highlights AXL as a Candidate Zika Virus Entry Receptor in Neural Stem Cells.Cell Stem Cell. 2016;18(5):591-6. DOI: 10.1016/j. stem.2016.03.012 PMID: 27038591

18. Tang H, Hammack C, Ogden SC, Wen Z, Qian X, Li Y, et al. Zika Virus Infects Human Cortical Neural Progenitors and Attenuates Their Growth. Cell Stem Cell. 2016;18(5):587-90. DOI: 10.1016/j.stem.2016.02.016 PMID: 26952870

19. World Health Organization (WHO). Situation report: Zika virus microcephaly, Guillain-Barré syndrome [Accessed 6 Jun 2016]. Geneva: WHO. Available from: http://apps.who.int/iris/ bitstream/10665/208816/1/zikasitrep_2Jun2016_eng.pdf?ua=1

20. Ministerio de Sanidad, Servicios Sociales e Igualdad. Gobierno de España. [Diagnosed cases]. [Accessed 6 Jun 2016]. Spanish. Available from: http://www.msssi.es/en/profesionales/ saludPublica/zika/casosDiagnosticados/home.htm

21. Bachiller-Luque P, Domínguez-Gil González M, ÁlvarezManzanares J, Vázquez A, De Ory F, Sánchez-Seco Fariñas MP. First case of imported Zika virus infection in Spain. Enferm Infecc Microbiol Clin. 2016;34(4):243-6. DOI: 10.1016/j. eimc.2016.02.012 PMID: 26994814

22. Bocanegra C. Zika virus infection in pregnant women in Barcelona, Spain. Clin Microbiol Infect. 2016;S1198 743X(16)30043-X. DOI: 10.1016/j.cmi.2016.03.025 PMID:27063354

\section{License and copyright}

This is an open-access article distributed under the terms of the Creative Commons Attribution (CC BY 4.0) Licence. You may share and adapt the material, but must give appropriate credit to the source, provide a link to the licence, and indicate if changes were made.

This article is copyright of the authors, 2016.

This article is copyright of the European Centre for Disease Prevention and Control, 2016. 